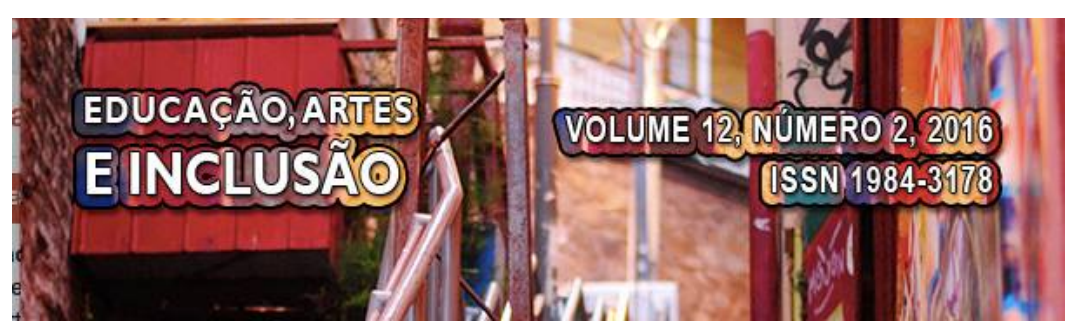

\title{
O ENSINO DE ARTES VISUAIS PARA ALUNOS COM ALTAS HABILIDADES E SUPERDOTAÇÃO
}

\section{THE TEACHING OF VISUAL ARTS TO STUDENTS WITH SUPERIOR CAPACITIES AND THE HIGHLY GIFTED}

DOI: http://dx.doi.org/10.5965/1984317812022016049

\author{
Juliana Moreno Cavalheiro, Vera Lucia Penzo Fernandes - UFMS
}

\begin{abstract}
RESUMO
O presente artigo apresenta uma análise do ensino de artes visuais para alunos com altas habilidades e superdotação, por meio do estudo de caso no Núcleo de Atividades às Altas Habilidades e Superdotação do município de Campo Grande, capital do Mato Grosso do Sul. O estudo parte de discussões sobre a legislação brasileira e traça um paralelo entre as políticas para o atendimento ao aluno, tendo como referência os documentos que versam sobre a educação especial. Entrevistas com duas professoras que atuam no Núcleo consolidam a aproximação empírica sobre o trabalho pedagógico dos professores de Artes Visuais para alunos com altas habilidades e superdotação. A partir da compreensão do funcionamento do Núcleo e das entrevistas, identificamos as seguintes categorias analíticas: as professoras de artes visuais do Núcleo de Atividades às Altas Habilidades e Superdotação; a seleção e a organização dos conteúdos; as metodologias de ensino e recursos materiais; os objetivos de ensino e a avaliação. Levando-se em conta que o aluno possui habilidades artísticas específicas de seu interesse, que devem ser desenvolvidas e enriquecidas, podemos afirmar que o papel do professor de Artes Visuais é fundamental no desenvolvimento de suas potencialidades.
\end{abstract}

PALAVRAS-CHAVES: educação especial, trabalho pedagógico, altas habilidades, artes visuais.

\begin{abstract}
This article presents an analysis of the teaching of Visual Arts to students with superior capacities and the highly gifted, through a case study in the Nucleus of Superior Capacities and the Highly Gifted in the municipality of Campo Grande, the state capital of the Brazilian state of Mato Grosso do Sul. It takes as its point of departure the discussions on Brazilian legislation and traces a parallel between the policies on attention meted to students, based on documents trading Special Education. Interviews with two teachers working in the Nucleus consolidated an empirical approximation on pedagogical labor of the teachers of Visual Arts of the Nucleus of Activities with Superior Capacities and the Highly Gifted. Starting with the comprehension of the functioning of the Nucleus and the interviews, the following analytical categories were identified: teachers of Visual Arts of the Nucleus of Activities with Superior Capacities and the Highly Gifted; the selection and organization of contents; the teaching methodologies and resource materials; the objectives of teaching and evaluation. Taking into consideration that the student with artistic abilities specific to his interests, who should be developed and enriched, it is possible to affirm that the role of the teacher of Visual Arts is fundamental in the development of his potential.
\end{abstract}

KEYWORDS: special education, pedagogical labor, superior capacities, visual arts. 


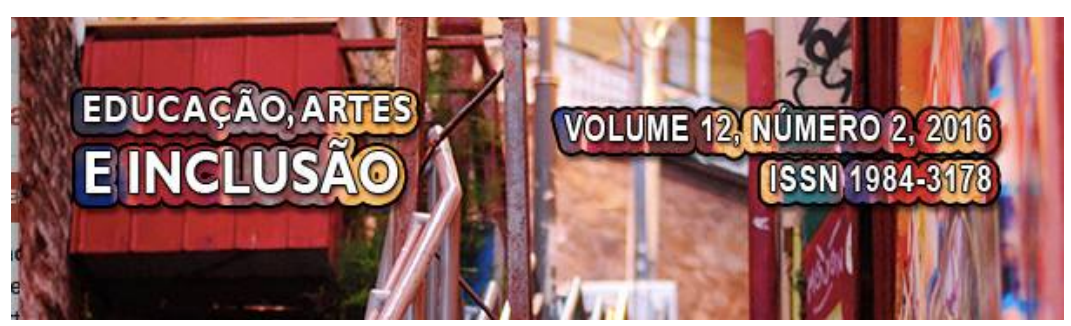

\section{INTRODUÇÃO}

Na perspectiva da educação inclusiva, a educação brasileira ainda enfrenta o desafio de tornar possível o acesso e a permanência dos alunos com necessidades educacionais especiais $^{1}$ na escola regular, bem como para o atendimento especializado. Políticas de educação inclusiva contribuíram e continuam contribuindo para a discussão e a implementação de ações que geram mudanças e adaptações no âmbito escolar desde a década de 1990.

No início dos anos de 1990, a Organização das Nações Unidas para a Educação, Ciências e a Cultura (UNESCO) coordenou um movimento internacional em apoio à Educação para Todos, na época foi assinado um acordo de cooperação com o Ministério da Educação do Brasil. A Declaração Internacional de Salamanca (1994) e as Diretrizes Curriculares Nacionais para a Educação Especial na educação Básica (2001) vinculadas à Lei de Diretrizes e Bases da Educação Nacional (LDB) (1996), também são alguns dos documentos elaborados no intuito de rever e reorganizar o sistema educacional nas últimas décadas com o objetivo de tornar possível a educação inclusiva. A conjuntura política e social é ampla, mas é neste contexto que nos inserimos para fazer o recorte para a realização de estudo sobre o trabalho pedagógico de professores de artes visuais com alunos com Altas Habilidades e Superdotação (AH/SD).

A LDB n॰ 9.394/1996 (BRASIL, 1996), estabelece diretrizes para a educação dos alunos com deficiência e com altas habilidades/superdotação. Os artigos 58, 59 e 60 são os que tratam especificamente da Educação Especial e da oferta de serviços de apoio especializados na escola regular para atender as peculiaridades de cada sujeito, bem como trata de assegurar que currículos, recursos educativos, organizações específicas, a formação de professores com especialização adequada e professores do ensino sejam capacitados para proporcionar a inclusão destes alunos. Neste cenário, passou a ser assegurada a efetiva inserção do aluno especial na escola regular e na vida em sociedade, o que não impediu a existência de atendimento especializado.

\footnotetext{
${ }^{1}$ A educação inclusiva está associada diretamente à educação especial, sendo que a educação especial atende aos alunos com deficiência, transtornos globais de desenvolvimento e altas habilidades/superdotação ou alunos com necessidades educacionais especiais.
} 


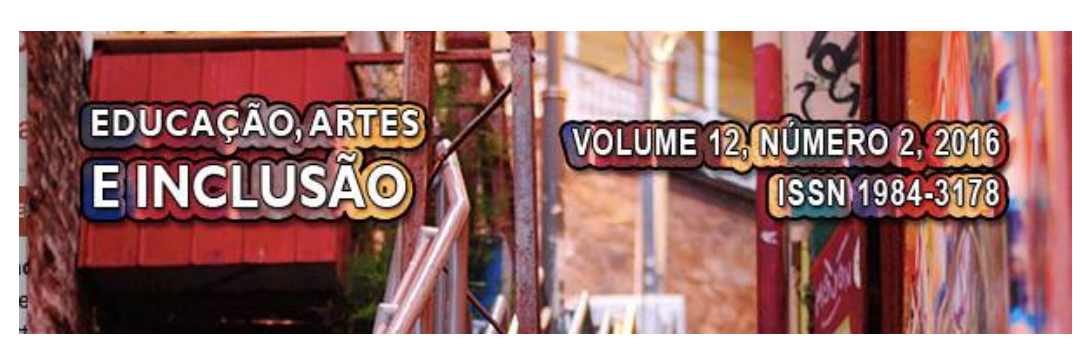

psicólogos). Neste contexto, "[...] construiu-se um conhecimento sobre as especificidades do ensino de arte, que busca contemplar as possibilidades e necessidades de cada grupo" (REILY, 2008, p. 237).

É de grande relevância a produção de conhecimentos através de pesquisas e práticas documentadas sobre como se constitui o ensino de artes no NAAH/S. O ensino de Artes Visuais pode contribuir para que alunos com AH/SD produzam novos conhecimentos, criem novos paradigmas e desenvolvam suas potencialidades, tanto no espaço da sala de aula, quanto nos Núcleos de atendimento.

Para possibilitar um ensino eficiente e de qualidade ao aluno com AH/SD se faz necessário uma relação de comunicação efetiva entre professor e aluno. Este processo de ensino e aprendizagem "[...] passa a ser pensado a partir de significações e entrelaçamentos que o professor faz entre o seu conhecimento sobre o aluno, sobre si mesmo e sobre o próprio conhecimento a ser explorado, incluindo também o contexto vivido por ele" (TACCA, 2006, p. 47). Assim, o professor é a peça fundamental no processo de construção do autoconhecimento e do conhecimento junto a seu aluno.

$\mathrm{O}$ trabalho pedagógico direcionado ao indivíduo com $\mathrm{AH} / \mathrm{SD}$ requer do professor estudos sobre as melhores estratégias a serem utilizadas em sala de aula. O professor, ao planejar, não pode esperar que a estratégia pedagógica seja única e suficiente para todos os alunos, esperando que a aprendizagem ocorra de forma homogênea. Tacca (2006 p. 48) ressalta que "[...] a ideia é a de que a estratégia pedagógica esteja orientada para o sujeito que aprende e não para o conteúdo a ser aprendido".

O processo de ensino e aprendizagem ocorre na relação entre pessoas, ou seja, na relação entre professor-aluno e aluno-aluno, e neste processo dialógico expressam seus pensamentos e sentimentos possibilitando a construção do conhecimento. É um processo interdependente. Conforme afirma Tacca (2006, p. 49) “[...] para ensinar alguém, antes de tudo é necessário identificar seus motivos e de que, nas situações de aprendizagem, há sempre uma convergência entre pensamento e emoção. Todo o processo reflexivo traz em si um aspecto motivacional".

Tacca (2006, p. 50) ressalta, também, que ensinar “[...] implica atuar procurando atingir a estrutura motivacional do aluno que se encontra unida aos processos de 


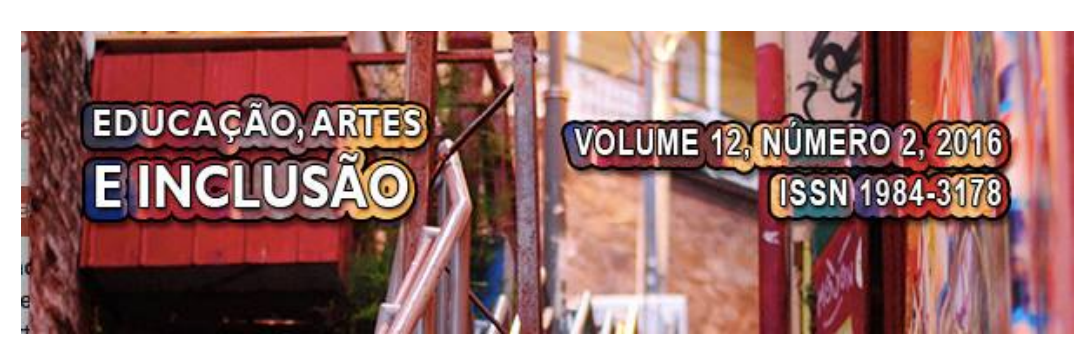

A organização dos conteúdos, a escolha dos métodos, a definição dos objetivos feitas pelo professor de artes visuais, devem considerar a diversidade social, cultural e cognitiva do aluno. A presença de um aluno especial na turma deve ter atenção no sentido de adequação dos conteúdos às capacidades do mesmo. Também deve-se considerar o conhecimento sobre os conteúdos da disciplina: se faz necessário que o professor possua conhecimentos na área de artes visuais para que o mesmo "[...] saiba encaminhar suas ações pedagógicas e dê condições para a realização desse processo", conforme esclarecem Fusari e Ferraz (2009, p. 141). A articulação entre os encaminhamentos metodológicos com os princípios norteadores do trabalho do professor, aos seus objetivos e aos conteúdos, resulta em um processo eficaz de ensino e aprendizagem da arte.

O professor, ao elaborar seu planejamento, deve considerar o currículo formal da escola onde trabalha. As ações, os valores, os compromissos assumidos, a escolha da metodologia a ser aplicada, devem estar relacionados ao currículo escolar, pois

[...] toda escola tem um currículo formal como suporte para sua tarefa político-pedagógica de educar crianças, jovens e adultos (de todas as idades). E que este currículo formal - materializado na grade de ensino - é fruto de uma síntese das leis em vigor (LDB), seus desdobramentos (PCNs, Conselhos Nacional, Estadual, Municipal de Educação) e orientações específicas das Secretarias Estaduais e Municipais. Este currículo formal é traduzido nas escolas em ementas, programas, planos e projetos de ensino, que dialogam com o Projeto Político Pedagógico da unidade escolar (FUSARI; FERRAZ, 2009, p. 144).

O professor, geralmente, realiza o seu planejamento em consonância com o currículo da escola, pois este disponibiliza os pressupostos necessários para o encaminhamento de um trabalho pedagógico adequado.

A partir de uma perspectiva contemporânea, o ensino e a aprendizagem de arte estão ligados aos aspectos culturais e às questões do cotidiano aos quais o professor e aluno estão inseridos. A intermediação do professor é fator imprescindível, pois cabe à ele proporcionar o desenvolvimento do aluno para a compreensão, a apreciação e o fazer artístico, permeados pelo conhecimento contextualizado. 


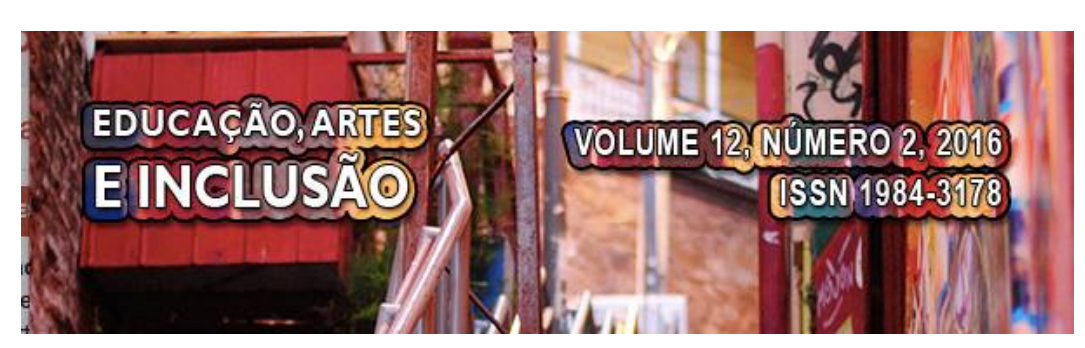

Conforme a pesquisa realizada no campo empírico, verificamos que as atividades desenvolvidas no Núcleo são planejadas e aplicadas a partir dos interesses e habilidades dos alunos, e estes, também são agentes ativos no processo de ensino e aprendizagem, pois, o planejamento, por exemplo, acaba sendo uma atividade desenvolvida em conjunto, já que professor e aluno decidem juntos, o quê e como vão realizar as atividades.

Os rumos de toda a ação pedagógica são discutidos em conjunto, com professores e alunos. Então, o NAAH/S tem alguns recursos e as professoras e os alunos também contribuem trazendo seus materiais de casa e compartilhando-os com os todos.

Enquanto são implementadas estratégias de ensino, previamente elaboradas, acontecem, concomitantemente, a avaliação contínua dos mesmos. Todas as etapas do processo de ensino e aprendizagem descritas neste trabalho, são permeadas pela intenção de proporcionar ao aluno com AH/SD o desenvolvimento pleno de suas potencialidades e habilidades.

O NAAH/S oferece atendimento individualizado, organizado em pequenos grupos, com um cronograma adequado às necessidades do aluno, possibilitando que os atendimentos ou atividades a serem desenvolvidas funcionem no contra turno do horário escolar, nos horários em que o aluno tenha disponibilidade. Vimos que muitos alunos que estudaram no $\mathrm{NAAH} / \mathrm{S}$, regressam com o intuito de continuarem vivenciando as experiências proporcionadas naquele espaço.

Em relação a organização ou seleção dos conteúdos, as professoras do NAAH/S partem da História da Arte e da curiosidade ou habilidade do próprio aluno, sem se preocupar em vincular estes conteúdos ao currículo escolar ou aos documentos curriculares existentes. Por fim, a referência parte dos alunos com o acompanhamento e a orientação das professoras de Artes Visuais. Além disso, outra referência comentada por uma das professoras diz respeito a metodologia triangular da Ana Mae Barbosa (2001), que interliga o fazer artístico, a história da arte e a análise da obra de arte.

$\mathrm{O}$ funcionamento do ensino de Artes Visuais no NAAH/S aponta um movimento dinâmico de experimentações práticas variadas, de pesquisas espontâneas e de uma organização e realização do trabalho pedagógico permeado por atitudes e posturas de colaboração e compartilhamento de materiais e de conhecimento. 


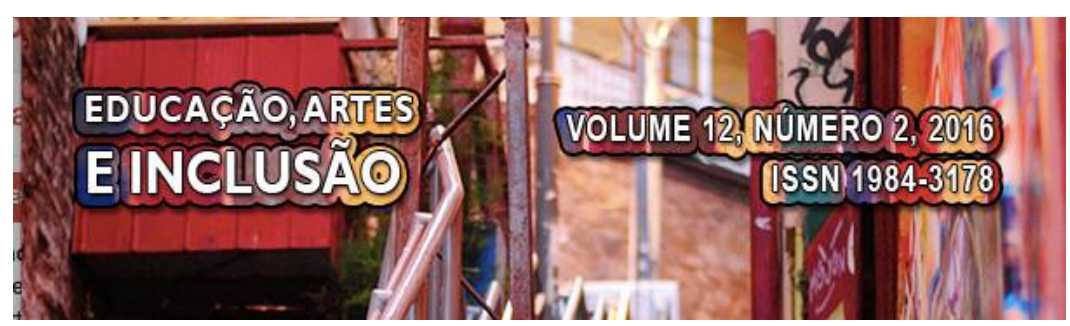

Disponível em $<$ http://portal.mec.gov.br/seesp/arquivos/pdf/altashabilidades.pdf $>$. Acesso em 05 de abril de 2015.

DECLARAÇÃO DE SALAMANCA: sobre princípios, políticas e práticas na área das necessidades educativas especiais, 1994. Disponível em: <http://unesdoc.unesco. org/images/0013/001393/139394por.pdf>. Acesso em 06 maio de 2015.

FERNANDES, Vera Lucia Penzo. A criatividade no trabalho pedagógico do professor de artes visuais no ensino médio, no contexto da educação inclusiva. 18 de outubro de 2011. 263 páginas. Tese de Doutorado. UFMS. Campo Grande 2011.

FREITAS, Soraia N.; PÉREZ, Susana G. P. B. Altas Habilidades/Superdotação: Atendimento especializado. $2^{\mathrm{a}}$ ed. Marília : abpee, 2012.

FUSARI, Maria F. de R.; FERRAZ, Maria Heloisa C.de T. Metodologia do ensino da arte: Fundamentos e proposições. $2^{\text {a }}$ Ed. rev.e ampl. São Paulo:Cortez, 2009.

JESUS, Denise M. de. (Org.) Inclusão, práticas pedagógicas e trajetórias de pesquisa. Porto Alegre: Mediação, 2007.

NOGUEIRA, Ana Paula. A criatividade no ensino de artes visuais para alunos com altas habilidades/Superdotação. Trabalho de Conclusão de Curso. UFMS. Campo Grande, 2011.

PILLOTTO, Silvia S. D; STAMM, Eliana. Fundamentos e metodologias do ensino de arte. Curitiba: Fael, 2011.

REILY, L. História, Arte, educação: reflexões para a prática de arte na educação especial in BAPTISTA, Claudio R. (Org.) Educação Especial: diálogo e pluralidade. Porto Alegre: Editora Mediação, 2008.

TACCA, Maria Carmen V. R. (Org.) Aprendizagem e Trabalho Pedagógico. Campinas: Editora Alínea, 2006.

UNESCO, Educação para todos. Disponível em: $<$ http://www.unesco.org /new/pt/brasilia/education/education-for-all/>. Acesso em setembro de 2015.

UNICEF, Disponível em: http://www.unicef.org/brazil/pt/resources 10230.htm>. Acesso em 20 setembro de 2015.

VIRGOLIM, Ângela M. R. Altas habilidades/Superdotação: encorajando potenciais. Ministério da Educação, Secretaria de Educação Especial. 1ª ed. Brasília, DF, 2007.

Altas Habilidades e desenvolvimento Intelectual. In: Desenvolvimento de talento e altas habilidades: orientações para pais e professores FLEITH, Denise Souza e Alencar, Eunice M. L. S. (Orgs). Porto Alegre: Ed. Artmed, 2007. 


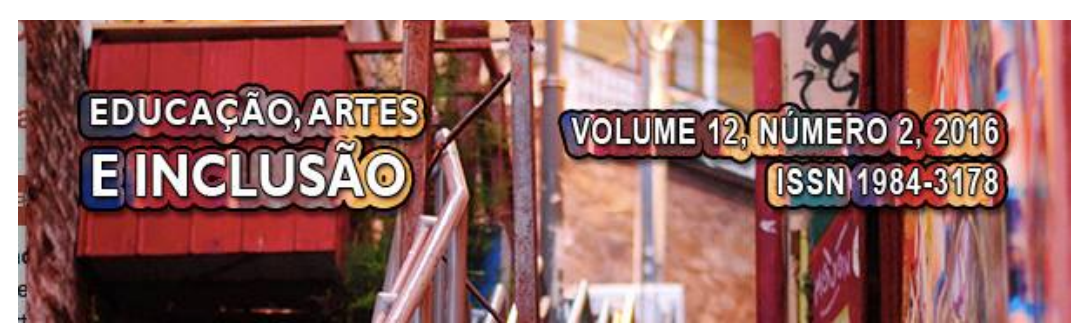

VIRGOLIM, Ângela M. Rodrigues; KONKIEWITZ, E. Castelon (Orgs.) Altas Habilidades/Superdotação: inteligência e criatividade: uma visão multidisciplinar. Campinas: Papirus, 2014.

Recebido em 30 de maio de 2016 Aprovado em 18 de julho de 2016 